\title{
Macroscopia, histopatologia e bacteriologia de fígados de frangos (Gallus gallus) condenados no abate
}

\author{
Gross, microscopic and bacteriologic evaluations of broiler chicken livers (Gallus gallus) condemned \\ at slaughter
}

\begin{abstract}
Aleverson da Silva Barcelos ${ }^{1}$ Maristela Lovato Flôres ${ }^{2}$ Glaucia Denise Kommers ${ }^{3}$ Vladimir Pinheiro do Nascimento $^{4}$ Stefanie Dickel Segabinazi ${ }^{2}$ Taiane Antoniazzi ${ }^{5}$ Joana Darc Lopes Bassan ${ }^{1}$
\end{abstract}

\section{RESUMO}

Este trabalho avaliou, através da macroscopia, histopatologia e bacteriologia, fígados de frangos (Gallus gallus) condenados no abate. Cem fígados de frango foram coletados na linha de inspeção. Noventa deles tinham sido condenados por apresentarem alterações macroscópicas. Dez fígados não apresentavam alterações macroscópicas. As coletas foram feitas em dois abatedouros localizados no Estado do Rio Grande do Sul. No laboratório, fez-se detalhada descrição das alterações macroscópicas dos fígados condenados e exames histopatológicos e bacteriológicos complementares. Para a descrição macroscópica, os seguintes parâmetros foram avaliados: forma, coloração, tamanho, consistência, odor $e$ presença de lesões visíveis. Foram observados fígados com alterações na cor, forma, tamanho e/ou consistência em 47/90 amostras; fígados marrom-pálidos e com outras alterações macroscópicas associadas perfizeram 19/90 amostras; 5/90 fígados estavam amarelos ou amarelados e com outras alterações macroscópicas associadas; 19/90 fígados estavam verdes ou esverdeados e com outras alterações macroscópicas associadas. Os principais diagnósticos histopatológicos foram de colângio-hepatite heterofílica multifocal, degeneração e/ ou necrose hepatocelular centrolobular e em ponte, hepatite necrosante aleatória, pericolangite heterofílica multifocal e peri-hepatite fibrinosa subaguda difusa acentuada. A bacteriologia foi direcionada para pesquisa de Escherichia coli, Salmonella spp. e Staphylococcus sp. Utilizando-se cultivo direto das amostras de fígado em meios de cultura seletivos, isolou-se E. coli em 26/100 amostras e Staphylococcus sp. em
24/100 amostras. Para pesquisa de salmonelas, utilizou-se a metodologia convencional preconizada para esta bactéria, entretanto não houve isolamento de nenhuma espécie deste gênero. Através das avaliações realizadas pode-se confirmar o predomínio de lesões sugestivas de infecção bacteriana nos fígados condenados.

Palavras-chave: fígado, frango de corte, inspeção de carnes, patologia, bacteriologia.

\section{ABSTRACT}

Gross, microscopic, and bacteriologic evaluations of broiler chicken livers condemned at slaughter were performed. One hundred broiler livers were sampled. Ninety of them had gross lesions and were condemned by the meat inspection service. Ten of them were grossly normal. The sampling was done in two processing plants located in the State of Rio Grande do Sul, Brazil. For the gross evaluation, the following parameters were considered: shape, color, size, texture, odor, and the presence of other visible lesions. Livers with changes in color, shape, size and/or texture were 47/90; brown-pale livers with other associated macroscopic lesions were 19/90; yellow or yellowish livers with other associated gross lesions were 5/90; and green or greenish livers with other associated lesions were 19/90. The main microscopic diagnoses consisted of multifocal heterophilic colangio-hepatitis, degeneration and/or centrilobular to bridging hepatocellular necrosis, random necrotizing hepatitis and multifocal heterophylic pericolangitis.

${ }^{1}$ Programa de Pós-graduação em Medicina Veterinária-Universidade Federal de Santa Maria (UFSM), Santa Maria, RS, Brasil. Rua General Daltro Filho, 102, 98025-630, Cruz Alta, RS, Brasil. E-mail: aleversonvet@brturbo.com.br. Autor para correspondência. ${ }^{2}$ Departamento de Medicina Veterinária Preventiva (DMVP), Laboratório Central de Diagnóstico de Patologias Aviárias, UFSM, Santa Maria, RS, Brasil.

${ }^{3}$ Departamento de Patologia, Laboratório de Patologia Veterinária, UFSM, Santa Maria, RS, Brasil.

${ }^{4}$ Faculdade de Veterinária, Centro de Diagnóstico de Patologias Aviárias, Universidade Federal do Rio Grande do Sul, Porto Alegre, RS, Brasil.

${ }^{5}$ Curso de Medicina Veterinária, UFSM, Santa Maria, RS, Brasil. 
The bacteriological evaluation was oriented to finding of Escherichia coli, Salmonella spp. and Staphylococcus sp. It was carried out by direct culture of the liver samples in selective culture media. E. coli was isolated in 26/100 samples and Staphylococcus sp. in 24/100 samples. For culturing of Salmonella spp., the conventional method indicated for this bacteria was utilized. However, there was no isolation of any species of the Salmonella genus. In all the three evaluations, a high incidence of lesions suggestive of bacterial infections was observed in the condemned livers.

Key words: liver, broiler chicken, meat inspection, pathology, bacteriology.

\section{INTRODUÇÃO}

O serviço oficial de inspeção sanitária dos abatedouros avícolas, representado pelo Serviço de Inspeção Federal (SIF) do Ministério da Agricultura Pecuária e Abastecimento (MAPA) e suas representações estaduais e municipais, constituem os órgãos responsáveis pela garantia de qualidade da carne e vísceras para o consumo (PONTES, 2004). Os critérios de condenação de vísceras de frango (Gallus gallus), especialmente do fígado, consideram o aspecto visual (cor, forma e tamanho), consistência e odor do órgão, de acordo com a Lei no 1283 de 18 de dezembro de 1950 (Regulamento de Inspeção Industrial e Sanitária de Produtos de Origem Animal - RISPOA), atualizada pela Portaria ํㅡㄴ 210 de 10 de novembro de 1998 do MAPA.

A condenação de carnes e vísceras impróprias para o consumo visa zelar pela saúde pública, uma vez que a carne de frango e seus subprodutos, assim como todos os produtos de origem animal, são uma das mais importantes fontes de enfermidades transmitidas por alimentos. O fígado de frango "in natura” ou processado é passível de sofrer contaminação bacteriana devido à sua constituição química, condições de obtenção e manipulação (JAY, 1994).

O fígado de frango pode ser acometido por inúmeras alterações que incluem distúrbios circulatórios, toxicoses, doenças infecciosas (virais, bacterianas, parasitárias) e neoplásicas. Muitas lesões hepáticas não são específicas quanto à etiologia, mas fornecem informações importantes sobre a ocorrência de doenças sistêmicas (HOERR, 1996).

O objetivo deste estudo foi determinar as principais causas de condenação de fígados de frangos nas amostras analisadas. Além dos parâmetros macroscópicos, semelhantemente aos utilizados pelo serviço de inspeção, foram realizados exames histopatológicos e bacteriológicos complementares, visando obter informações mais acuradas sobre as doenças que acometem frangos de corte e que são responsáveis por perdas econômicas na avicultura.

\section{MATERIAL E MÉTODOS}

Através da macroscopia, histopatologia e bacteriologia, esta última dirigida à pesquisa de Salmonella spp., Escherichia coli e Staphylococcus sp., foram avaliados 100 fígados de frangos (Gallus gallus) "in natura" coletados em dois abatedouros de frangos do Estado do Rio Grande do Sul.

Macroscopicamente, 90 fígados apresentavam alterações, sendo conseqüentemente, condenados por técnico do Serviço de Inspeção de Produtos de Origem Animal. Dez fígados não apresentavam alterações macroscópicas, sendo, portanto, fígados que seriam liberados para o consumo. Os parâmetros utilizados para a descrição das alterações macroscópicas, realizada no Laboratório Central de Diagnóstico de Patologias Aviárias (LCDPA) - UFSM, foram a coloração, forma, tamanho, consistência, odor e a presença ou não de lesões ao exame visual.

Para a avaliação microscópica, amostras dos 100 fígados foram fixadas em formol a $10 \%$ e processadas rotineiramente para histopatologia no Laboratório de Patologia Veterinária (LPV) - UFSM. Duas seções histológicas de cada fígado foram examinadas sob microscopia de luz. Esta avaliação foi feita sem o conhecimento prévio dos resultados bacteriológicos.

Na pesquisa de Salmonella spp., de cada um dos 100 fígados foram retirados 2,5g de tecido, sendo processados conforme a metodologia para pesquisa dessa bactéria sugerida por SIQUEIRA (1995), compreendendo as etapas de pré-enriquecimento em água peptonada $1 \%$; enriquecimento seletivo em caldos Tetrationato e Rappaport-Vassiliadis; plaqueamento em meios sólidos ágar MacConkey e ágar Rambach e identificação bioquímica utilizando-se os meios três açúcares e ferro (TSI), ágar lisina-ferro (LIA), meio SIM (Sulphide Indol Motility), caldo uréia (prova hidrólise da uréia), meio vermelho de metila(VM), Voges-Proskauer (VP) e citrato de Simmons.

Foram então realizadas leitura e interpretação das provas bioquímicas de acordo com QUINN et al. (1994). Nas colônias suspeitas de Salmonella spp., foram realizadas provas sorológicas com antisoro polivalente $\mathrm{O}$.

Para investigação da presença das bactérias Escherichia coli e Staphylococcus sp. a superfície dos fígados foi flambada com espátula incandescente e, posteriormente, uma alça de platina foi inserida no local flambado e na seqüência estriada em placas com meios 
de cultura. No processo, foram utilizados ágar sangue e ágar MacConkey para a pesquisa de $\boldsymbol{E}$. coli e ágar Baird-Parker e ágar sangue para pesquisa de Staphylococcus sp. As placas foram incubadas em estufa bacteriológica a $37^{\circ} \mathrm{C} / 24-48$ horas. A identificação de Staphylococcus sp. foi feita pela coloração de Gram e teste de catalase, conforme OLIVEIRA(2000).

Colônias suspeitas de $\boldsymbol{E}$. coli foram semeadas nos tubos com os meios TSI, Citrato, Urease, SIM e LIA, os quais foram incubados em estufa bacteriológica a $37^{\circ} \mathrm{C} / 24$ horas para identificação bioquímica. A leitura e interpretação das provas bioquímicas foram feitas de acordo com QUINN et al. (1994). A análise bacteriológica para Escherichia coli e Staphylococcus sp. foi feita a partir de amostras refrigeradas por um período não superior a 24 horas, tempo decorrido entre a coleta e o processamento no laboratório.

\section{RESULTADOS E DISCUSSÃO}

$\mathrm{Na}$ macroscopia, dez fígados foram considerados normais no que se refere à cor, forma, tamanho, consistência e odor. As alterações macroscópicas observadas nos noventa fígados condenados variaram significativamente. Neste estudo, a cor do órgão foi considerada como um dos principais parâmetros macroscópicos para descrição das alterações macroscópicas. Foram observados fígados marrom-pálidos (19/90), verdes ou esverdeados (19/ 90), amarelos ou amarelados (5/90) e fígados cuja principal alteração não residia exclusivamente na cor do órgão, e sim em um conjunto de alterações envolvendo a cor, forma, tamanho e/ou consistência (47/90).

Associadas às alterações geralmente difusas na coloração, foram também observadas diversas alterações macroscópicas que provavelmente contribuíram para que os mesmos fossem condenados, tais como áreas ou manchas claras em 17/90 amostras, aumento de volume em 25/90, engrossamento de bordas em 21/90 amostras e pontos brancos multifocais ou coalescentes em 34/90 amostras. Essas alterações podem ter etiologias variadas e, em geral, os processos septicêmicos que comumente acometem frangos determinam graus variáveis de comprometimento hepático, de modo que tão somente pela observação macroscópica do órgão na maioria das vezes se torna muito difícil determinar a doença específica, necessitandose exames complementares (BORDIN, 1978).

Apesar de não ter sido possível estabelecer uma correlação constante e direta entre as alterações macroscópicas observadas e os achados microscópicos listados na tabela 1 (coluna de diagnósticos morfológicos), provavelmente devido aos diferentes graus de severidade e à duração variável das lesões, pôde-se observar alguns aspectos macroscópicos mais tipicamente relacionados aos respectivos diagnósticos morfológicos, os quais estão ilustrados na figura 1.

Na microscopia (sumarizada na Tabela 1), observou-se que em 21/100 amostras o diagnóstico morfológico foi de colângio-hepatite heterofílica multifocal. Nesses fígados, havia lesões com severidade leve, moderada ou acentuada, infiltrados heterofílicos (ou, em menor intensidade, linfo-histiocitários) intraductais, periportais e estendendo-se ao parênquima hepático. Hiperplasia de ductos biliares, bilestase ductal, fibrose periportal, necrose multifocal e granulomas heterofílicos foram observados associados a essa lesão. Em 9/100 amostras, havia pericolangite heterofílica multifocal constituída por acentuado infiltrado periportal heterofílico, necrose multifocal leve e hiperplasia de ductos biliares leve a acentuada. Bilestase ductal, degeneração gordurosa e hemorragia multifocal leve foram ocasionalmente vistas.

Apesar de não serem específicas, colângiohepatite e pericolangite heterofílicas são lesões sugestivas de infecção por Clostridium perfringens em frangos de corte (RANDALL \& REECE, 1996). LOVLAND \& KALDHUSDAL (1999) observaram alterações consistentes com hepatite associada a Clostridium perfringens, as quais eram semelhantes às vistas neste estudo, em 33/45 amostras de fígados de frangos condenados no abatedouro. Embora a bactéria Clostridium perfringens não tenha sido incluída neste estudo, foi expressivo (30\%) o seu possível envolvimento nos diagnósticos de hepatite bacteriana. A manipulação da dieta e a natureza da ração das aves podem afetar a população intestinal de Clostridium perfringens, favorecendo a emergência de enfermidades associadas a essa bactéria em frangos (WAGES \& OPENGART, 2003).

Em 36/100 fígados, observou-se hepatite necrosante de distribuição aleatória associada a fibrina, infiltrados e granulomas heterofílicos, sugestiva de hepatite bacteriana (HOERR, 1996; RANDALL \& REECE, 1996). Dentre estas, duas amostras apresentavam múltiplos aglomerados de bactérias cocóides basofílicas em áreas focalmente extensas de necrose, sendo sugestivo de infecção por Staphylococcus aureus (RANDALL \& REECE, 1996). Necrose multifocal leve associada à microtrombose sinusoidal foi observada em 9 destas 36 amostras. Esses achados não são patognomônicos, mas muito 
Tabela 1 - Resultados da histopatologia e bacteriologia de fígados de frango (Gallus gallus) condenados no abate.

\begin{tabular}{|c|c|c|c|c|}
\hline \multirow[b]{2}{*}{ Diagnóstico morfológico } & \multicolumn{2}{|l|}{ Histopatologia } & \multicolumn{2}{|c|}{ Bacteriologia } \\
\hline & Amostras & Comentário & Escherichia coli & Staphylococcus sp. \\
\hline $\begin{array}{l}\text { Colângio-hepatite } \\
\text { heterofílica multifocal }\end{array}$ & $\begin{array}{l}\text { 67, 68, 69, 70, 72, 73, 74, } \\
75,76,77,78,81,87,89 \\
91,93,94,96,97,98 \text { е } 99\end{array}$ & $\begin{array}{l}\text { Sugestivo de infecção } \\
\text { subaguda a crônica por } \\
\text { Clostridium perfringens }\end{array}$ & $\begin{array}{l}67,70,73,74, \\
75,76,78,91 \mathrm{e} \\
94\end{array}$ & 67 \\
\hline $\begin{array}{l}\text { Degeneração e/ou necrose } \\
\text { hepatocelular centrolobular } \\
\text { e em ponte }\end{array}$ & $10,16,18,32,34$ e 38 & $\begin{array}{l}\text { Sugestivo de lesão } \\
\text { secundária à hipóxia }\end{array}$ & 32 & 32 e 34 \\
\hline $\begin{array}{l}\text { Hepatite necrosante } \\
\text { aleatória }\end{array}$ & $\begin{array}{l}01,06,13,14,19,20,21, \\
26,28,31,35,49,51,54, \\
55,57,59,61,63,64,71, \\
82,83,88 \text { e } 90\end{array}$ & $\begin{array}{l}\text { Sugestivo de hepatite } \\
\text { bacteriana }\end{array}$ & $\begin{array}{l}01,21,49,61 \\
64 \text { e } 71\end{array}$ & $\begin{array}{l}01,13,14,21 \mathrm{e} \\
49\end{array}$ \\
\hline $\begin{array}{l}\text { Hepatite necrosante } \\
\text { aleatória com bactérias } \\
\text { basofílicas intralesionais }\end{array}$ & 7 e 36 & $\begin{array}{l}\text { Sugestivo de infecção por } \\
\text { Staphylococcus aureus }\end{array}$ & 36 & 36 \\
\hline $\begin{array}{l}\text { Hepatite necrosante } \\
\text { aleatória com } \\
\text { microtrombose sinusoidal }\end{array}$ & $\begin{array}{l}4,9,29,39,46,47,53,56 \text { e } \\
58\end{array}$ & $\begin{array}{l}\text { Sugestivo de infecção aguda } \\
\text { por Escherichia coli }\end{array}$ & 09, 39 е 56 & 09 e 39 \\
\hline $\begin{array}{l}\text { Pericolangite heterofílica } \\
\text { multifocal }\end{array}$ & $\begin{array}{l}3,5,30,45,50,80,85,86 \\
\text { е } 92\end{array}$ & $\begin{array}{l}\text { Sugestivo de infecção aguda } \\
\text { por Clostridium perfringens }\end{array}$ & 85 е 92 & $\begin{array}{l}03,30,80,85 \text { e } \\
86\end{array}$ \\
\hline $\begin{array}{l}\text { Peri-hepatite fibrinosa } \\
\text { subaguda difusa acentuada }\end{array}$ & 22 e 24 & $\begin{array}{l}\text { Sugestivo de infecção por } \boldsymbol{E} \text {. } \\
\text { coli (colisepticemia) }\end{array}$ & - & 24 \\
\hline Outras alterações & $\begin{array}{l}2,8,11,15,17,23,25,27 \\
33,37,48,52,65 \text { e } 66\end{array}$ & Inespecíficas & 27 е 65 & $15,17,65$ e 66 \\
\hline Sem alterações & $\begin{array}{l}12 *, 40,41,42,43,44,60 \\
62,79,84,95 \text { e } 100^{*}\end{array}$ & $\begin{array}{l}\text { Sem alterações } \\
\text { *Com alterações } \\
\text { macroscópicas }\end{array}$ & 44 e 95 & 44,84 е 95 \\
\hline
\end{tabular}

sugestivos de infecção aguda por Escherichia coli (HOERR, 1996; RANDALL \& REECE, 1996).

Em 2/100 amostras, observou-se perihepatite fibrinosa subaguda difusa acentuada caracterizada por espessamento do saco hepatoperitonial e da cápsula hepática em consequêencia de depósitos de fibrina em organização, heterófilos, linfócitos e macrófagos, compatível com colisepticemia (RANDALL \& REECE, 1996).

Em 6/100 fígados, observaram-se alterações compatíveis com lesão de hipóxia, com achados microscópicos de lesão aguda (5/6, com degeneração e/ou necrose hepatocelular centrolobular e em ponte) ou de lesão crônica (1/6, com dilatação dos sinusóides, atrofia de cordões de hepatócitos e espessamento difuso da cápsula hepática). As lesões agudas e crônicas observadas neste estudo são indicativas de hipóxia secundária à insuficiência cardíaca direita
(HOERR, 1996; RANDALL \& REECE, 1996). NAKAMURA et al. (1999) observaram alterações histopatológicas que consistiam de degeneração e necrose de hepatócitos e fibrose da cápsula hepática em 64 de 67 casos de ascite em conseqüência de falência cardíaca.

Em 14/100 amostras, observaram-se alterações microscópicas inespecíficas ou sem significado clínico, tais como congestão e hemorragias multifocais (1/14), deposição de glicogênio nos hepatócitos (2/14), bilestase ductal (5/14) e degeneração gordurosa (6/14). Os dez fígados considerados normais macroscopicamente não apresentaram alterações microscópicas.

Pela análise bacteriológica, observa-se, na tabela 1, que nas lesões sugestivas de infecção por Escherichia coli (11/100), houve isolamento desta bactéria em 3/11 amostras. Um número de isolados 


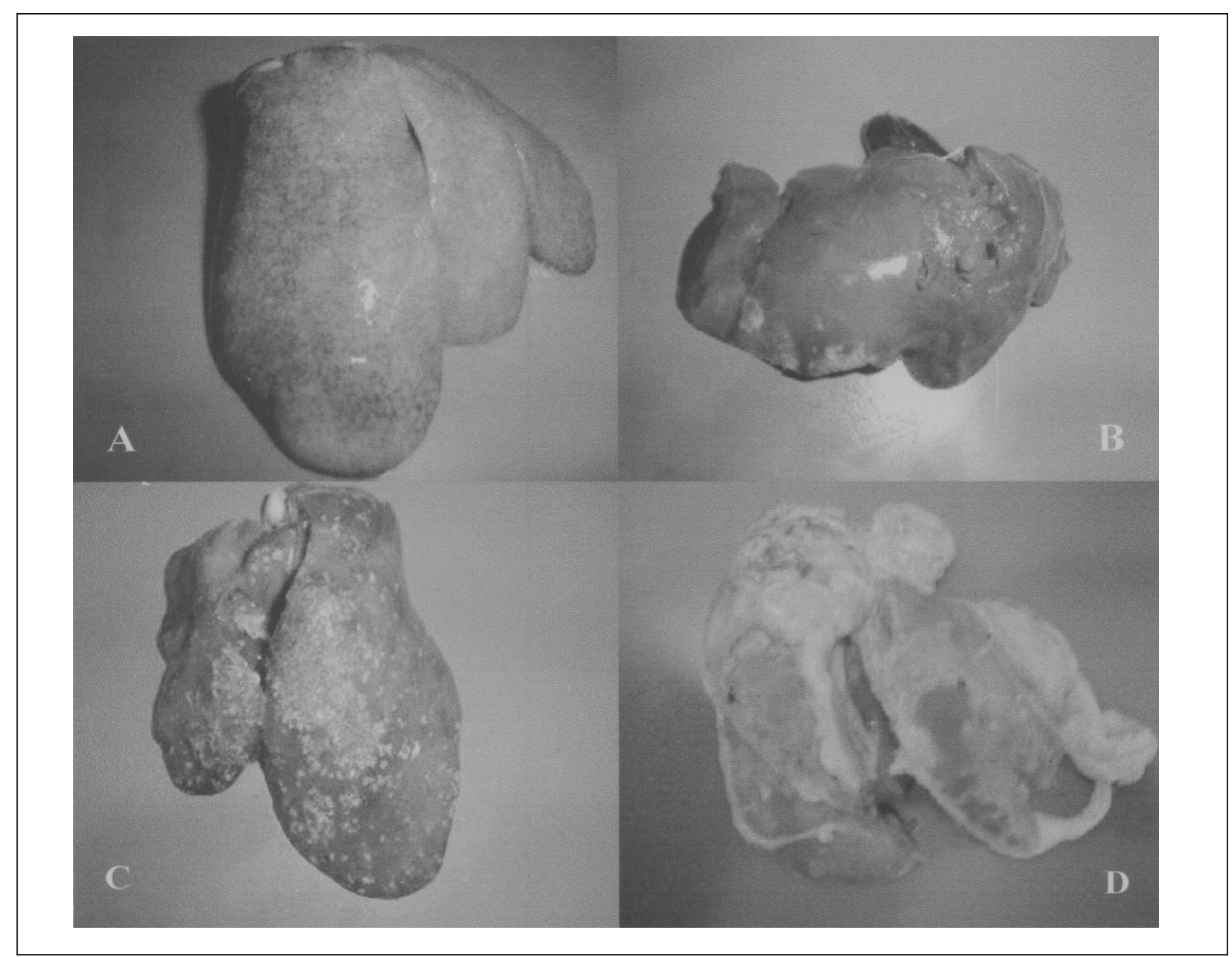

Figura 1 - Fígados de Gallus gallus. Aspectos macroscópicos mais tipicamente relacionados aos respectivos diagnósticos morfológicos. A) Colângio-hepatite heterofílica multifocal, sugestiva de infecção por Clostridium perfringens. Observa-se acentuação do padrão lobular e aumento de volume com bordas arredondadas. B) Hepatite necrosante sugestiva de infecção por Staphylococcus aureus. Há áreas claras multifocais a coalescentes próximos aos bordos. C) Hepatite necrosante de distribuição aleatória, sugestiva de infecção bacteriana. Há intenso pontuado branco multifocal a coalescente na superfície capsular. D) Peri-hepatite fibrinosa, compatível com infecção por Escherichia coli.

significativamente maior, chegando a 29 em 30 amostras, foi observado em outro estudo (LEITE, 1995). Tal diferença também pode ser vista quanto ao isolamento de Staphylococcus onde o mesmo autor isolou Staphylococcus aureus em 27/30 fígados. No presente estudo, das duas amostras com lesões sugestivas de infecção por Staphylococcus aureus (2/ 100), isolou-se Staphylococcus sp. em apenas uma.

Deve-se considerar que LEITE (1995) realizou as análises bacteriológicas em fígados de frangos resfriados, a partir de subamostras de $10 \mathrm{~g}$ de fígado, macerado e pré-enriquecido em água peptonada a $10 \%$, diferentemente da metodologia empregada neste estudo, no qual as semeaduras em meios seletivos foram feitas a partir de uma alça de platina flambada e inserida internamente no órgão, com a superfície de contato do mesmo também flambada com espátula incandescente, descartando-se, dessa forma, qualquer contaminação externa. Em caso de semeaduras diretas a partir de vísceras, ou seja, sem qualquer forma de enriquecimento da amostra, devem ser consideradas as chances de redução de isolados bacterianos (OLIVEIRA, 2000).

O tempo de infecção também pode influenciar o número de isolados bacterianos. FISHER et al. (1998) em inoculação experimental de $\boldsymbol{E}$. coli, Staphylococcus aureus e Pasteurela multocida em frangos, no intuito de determinar se as septicemias podem ser detectadas em órgãos viscerais de frangos antes do surgimento de alterações musculares esqueléticas, sugerem que não há uma relação linear entre o lapso de tempo de infecção transcorrido e os 
isolamentos bacterianos. Entretanto, segundo os autores, em casos de infecção por $\boldsymbol{E}$. coli parece ocorrer uma queda no número de isolados 144 horas pósinfecção.

Em relação ao Staphylococcus sp., alguns autores sugerem um decréscimo nos isolamentos 44 dias pós-infecção experimental em perus. Acrescentam ainda que perus saudáveis foram colonizados com $S$. aureus, sugerindo que a colonização não levaria necessariamente ao desenvolvimento da doença clínica (JENSEN et al., 1987), fato que poderia explicar em nosso trabalho o isolamento de Staphylococcus sp. em 3 amostras sem alterações macroscópicas e histopatológicas.

Na tabela 1, observa-se que as bactérias $\boldsymbol{E}$. coli e Staphylococcus sp. foram isoladas, respectivamente, em 11/30 e em 6/30 fígados com diagnóstico sugestivo de infecção por Clostridium perfringens, evidenciando a possibilidade de infecção mista. Em 25/100 amostras com diagnóstico de hepatite necrosante compatível com hepatite bacteriana obtevese isolamento de $\boldsymbol{E}$. coli em seis amostras e Staphylococcus sp. em cinco. Baseado no diagnóstico morfológico, 68/100 fígados apresentaram lesões microscópicas variadas (colângio-hepatite, hepatite necrosante, pericolângite e peri-hepatite), porém todas sugestivas de etiologia bacteriana, sendo a bactéria $\boldsymbol{E}$. coli isolada em 21 amostras e Staphylococcus sp. em 15 amostras analisadas.

Não foram observadas lesões microscópicas indicativas de infecção por Salmonella spp. neste estudo. As infecções por bactérias do gênero Salmonella podem lembrar outras infecções bacterianas agudas, porém apresentam características áreas multifocais a coalescentes de necrose de hepatócitos acompanhadas de inflamação linfocítica. Inflamação linfocítica multifocal permanece como uma seqüela da necrose induzida por Salmonella spp., embora isto não seja específico. Salmonella Gallinarum, causadora do tifo aviário, provoca anemia hemolítica extravascular com aumento de volume e coloração bronzeada do fígado devido à eritrofagocitose e hemossiderose (HOERR, 1996). Aglomerados de bastonetes podem ser observados em seções histológicas de fígados durante a infecção por Salmonella Enteritidis (RANDALL \& REECE, 1996).

A ausência de Salmonella spp. concorda com outra avaliação bacteriológica de miúdos de frangos (CARVALHO et al., 1994). Entretanto, outros autores analisaram fígados de aves obtidos em abatedouros comerciais e verificaram que 2/15 fígados apresentaram-se positivos para Salmonella spp. (FREITAS et al., 1986). Salmonelas foram isoladas em $9 / 36$ pools de fígados de frangos condenados pelo SIF em um abatedouro do estado de Goiás, sendo em sete, isolamento de Salmonella Enteritidis e em dois, Salmonella Typhimurium (OLIVEIRA et al., 2004).

\section{CONCLUSÕES}

As alterações macroscópicas observadas nos 90 fígados condenados foram muito variáveis, inclusive para um mesmo diagnóstico morfológico obtido pela histopatologia, não sendo possível estabelecer uma correlação constante das lesões macroscópicas e os diagnósticos morfológicos. Do total de 100 fígados de frangos analisados, 68 apresentaram lesões microscópicas sugestivas de infecção bacteriana. Nestes, Escherichia coli foi isolada em 21 e Staphylococcus sp. em 15 amostras. Não houve isolamento de Salmonella spp. em fígados com lesões sugestivas de infecção bacteriana, bem como não foram observadas lesões microscópicas indicativas de infecção por esta bactéria. Concluiu-se também que os critérios de condenação foram eficientes, descartando fígados com risco potencial de transmissão de enfermidades.

\section{REFERÊNCIAS}

BORDIN, E.L. Diagnóstico post-mortem em avicultura. São Paulo: Nobel, 1978. 165p.

CARVALHO, J.C.A.P. et al. Avaliação bacteriológica de miúdos (frangos). In: CONGRESSO BRASILEIRO DE MEDICINA VETERINÁRIA, 1994, Olinda, PE. Anais... Recife : Sociedade Brasileira de Medicina Veterinária, 1994. p.23.

FISHER, M.E. et al. Postmortem detection of acute septicemia in broilers. Avian diseases, Ames, v.42, n.3, p.452-461, 1998.

FREITAS, M.Q. et al. Ocorrência de microorganismos da família Enterobacteriaceae em fígados de aves obtidos em abatedouros comerciais. In: CONGRESSO BRASILEIRO DE CIÊNCIA E TECNOLOGIA DE ALIMENTOS, 1986, Curitiba, PR. Anais... Curitiba : Sociedade Brasileira de Ciência e Tecnologia de Alimentos, 1986. p.9.

HOERR, F.J. Liver. In.: RIDDELL, C. Avian histopathology. Pensylvania: Library of Congress, 1996. p.143-166.

JAY, J.M. Microbiologia moderna de los alimentos. 3.ed. Zaragoza: Acribia, 1994. 804p.

JENSEN, M.M. et al. Staphylococcosis of turkeys. 1. Portal of entry and tissue colonizations. Avian Diseases, Ames, v.31, n.1, p.64-69, 1987.

LEITE, I.C.B. Avaliação bacteriológica de fígados de frangos (Gallus gallus domesticus) resfriados, comercializados no município do Rio de Janeiro-RJ. 1995. 87f. Dissertação (Mestrado em Higiene Veterinária e 
Processamento Tecnológico de Produtos de Origem Animal) Faculdade de Veterinária, Curso de Pós-graduação em Medicina Veterinária, Universidade Federal Fluminense.

LOVLAND, A.; KALDHUSDAL, M. Liver lesions seen at slaughter as an indicator of necrotic enteritis in broiler flocks. FEMS Immunology and Medical Microbiology, Rotterdam, n.24, p.345-351, 1999.

NAKAMURA, K. et al. Comparative pathology of heart and liver lesions of broiler chickens that died of ascites, heart failure, and others. Avian diseases, Ames, v.43, n.3, p.526-532, 1999.

OLIVEIRA, A.S.C. et al. Perfil de resistência a antimicrobianos de Salmonella Enteritidis e Salmonella Thyphimurium isoladas de miúdos de aves em Goiás. Revista Brasileira de Ciência Avícola, Campinas, Suplemento 6, p.195, 2004.

OLIVEIRA, S.J. Guia bacteriológico prático: microbiologia veterinária. Canoas: ULBRA, 2000. 237p.
PONTES, A.P. Programa de controle de Salmonella em abatedouros de aves. In: CONFERÊNCIA APINCO DE CIÊNCIA E TECNOLOGIA AVÍCOLA, 2004, Santos, SP. Anais... São Paulo: Fundação Apinco de Ciência e Tecnologia Avícolas, 2004. p.102.

QUINN, P.J. et al. Clinical veterinary microbiology. London: Mosby, 1994. 648p.

RANDALL, C.J.; REECE, R.L. Color atlas of avian histopathology. Turin: Mosby-Wolfe, 1996. 232p.

SIQUEIRA, R.S. Manual de microbiologia de alimentos. Brasília: Embrapa, 1995. 159p.

WAGES, D.P.; OPENGART, K. Necrotic enteritis. In.: SAIF, Y.M. Diseases of poultry. 11.ed. Ames, Iowa: Iowa State, 2003. p.781-783. 